\title{
Biomechanical analysis of the free combat positive thrust kick based on three-dimensional image.
}

\author{
Zhang Wenli* \\ Shijiazhuang City, Hebei Province, PR China
}

\begin{abstract}
The development of sports is of great significance to the development of the human body and the improvement of the comprehensive ability. Nowadays, with the rapid development of China's economy, there is a certain degree of advance in the development of sports, and it provides more opportunities for the development of sports in china because of the progress of computer technology. In this study, some technical actions of free combat were taken as an example to analyse the influence of the new threedimensional image technology on free combat thrust kick. The analysis results show that the application of three-dimensional images can make the free combat thrust kick more accurate.
\end{abstract}

Keywords: 3D image, Free combat, Positive kick, Sports.

Accepted on June 2, 2017

\section{Introduction}

In today's era, sports have become an important area and industry of the development of the times. The development of sports is of great practical significance to the whole world. Sports can meet people's physical fitness, but also can further improve people's spiritual level of pleasure and happiness, so that people's physical and mental health can be improved to a large extent. In order to improve the comprehensive strength of the country, the development of the sports industry and field is one of the most important research directions in the present era.

The application of computer technology has brought a positive role in the development of sports field. With the further integration of computer technology and the sports industry, the development of the sports industry is more efficient. This study mainly focuses on the research and analysis of some technical actions of free combat, so as to determine the importance of computer technology for free combat learning and play, and provide some theoretical basis for other sports learning.

\section{State of the Art}

\section{Research Status of free combat at home and abroad}

As one of the most important sports in the sports industry, free combat can further improve the coordination ability of athletes, and make the athlete's body muscle training more powerful and further make the physical fitness and physical quality of the athletes continuously improved. Nowadays, free combat has become a popular sport. Because free combat has a high performance; and in this sport, the requirements for the physical fitness of the athletes are high [1]. In the process of popularization, more and more theories have been mentioned gradually, the development of these new and more systematic theories has not only made the relevant technical theories of this kind of sports get a certain degree of improvement, but also has made this kind of sports developed to a greater extent, so as to enhance the physical fitness of athletes and provides a theoretical support for the national sports comprehensive ability.

\section{The application of $3 D$ image}

With the rapid development of computer technology, some new technologies have begun to come into being. Among them, 3D image technology is one of the important application technologies in the present age. Due to the application of twodimensional images, people can't carry out the detailed analysis of the contents of the study and generalization, thus there may be a certain degree of omission in the course of the study, this also gives birth to the development of threedimensional imaging technology and promotion [2]. Nowadays, the theories and technologies of 3D image have been applied in many fields and industries, which is of great significance to the development of industry and field. This technology has also begun to be used in the sports industry. Sports players can be based on the three-dimensional image technology to carry out a deeper analysis for the movement, so that they can better grasp and familiar with the relevant actions, so as to further provide technical support.

Table 1. Analysis of the relevant personnel.

\begin{tabular}{llll}
\hline Personnel level of Average age & $\begin{array}{l}\text { The proportion } \\
\text { people }\end{array}$ & $\begin{array}{l}\text { of men and } \\
\text { women }\end{array}$
\end{tabular}




\begin{tabular}{llll}
\hline Sports school students & 20 & 19.8 & $1.5: 1$ \\
\hline Sports teacher & 20 & 34.6 & $1.2: 1$ \\
\hline Other staff & 20 & 39.2 & $0.9: 1$ \\
\hline Total & 60 & 31.2 & $1.2: 1$ \\
\hline
\end{tabular}

\section{Methodology}

\section{Analysis of the current situation of free combat in China}

With the development of China's economy, China's various industries have made some progress, including the development of China's sports industry. However, there are still some problems in the development of sports in our country, which hinders the development of sports in our country to a certain extent. While the development of new science and technology has also brought some opportunities for China's sports industry and field. Therefore, the purpose of this study is to analyse the application of three-dimensional image technology in free combat in China, so as to analyse the importance of three-dimensional technology.

\section{Research methodology}

Firstly, the relevant data was analysed and summarized to make the relevant theory more clear and further provide a theoretical support for the follow-up study.

Secondly, the relevant changes of free combat athletes before and after the application of three-dimensional images were analysed and compared, and the superiority of threedimensional images was further confirmed. The investigator's situation is shown in Table 1.

\section{Result Analysis and Discussion}

\section{Biomechanical analysis of the free combat positive thrust kick based on three-dimensional image}

According to the survey results, the author thinks that the $3 \mathrm{D}$ imaging technology can make the preparation movement, physical coordination, action accuracy and other characteristics of the athletes further improved because of its perfect image data (Figure 1), it is of great significance to the biomechanics of athletes, therefore, it is worthy of being respected and developed to provide more accurate methods and techniques for the development of athletes.

\section{Analysis on the influence of three-dimensional imaging technology on free combat athletes' physique}

Through the investigation of the relevant investigators, the study thinks that compared with the traditional training methods, the biomechanical characteristics of all aspects of the free combat personnel have a certain degree of progress under the influence of the three-dimensional imaging technology. Compared with the traditional method, this technology is more adapted to the current development of free combat sports; so as to rely on the relevant methods can further improve the athletes' movements and physical fitness.

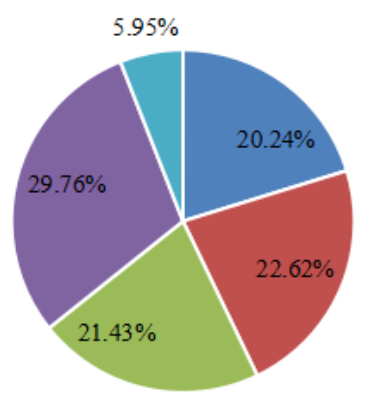

- Ready action $\mid$ Action coordination $\mid$ Veracity $\mid$ Accuracy $\mid$ Other

Figure 1. Biomechanical analysis of the free combat positive thrust kick based on three-dimensional image.

\section{Conclusions}

Nowadays, with the development trend of the times, the sport has gradually become an important part of the development of the world. Through the development of sports, the comprehensive strength of the world and the country can be further enhanced. However, the theories of sports are not enough in China. In view of this phenomenon, this research mainly carried out the biomechanical analysis of the free combat positive thrust kick based on three-dimensional image. The results show that the three-dimensional image has great significance and influence on the biomechanics of the free combat positive thrust kick, the purpose of this study is to provide a theoretical basis for the development of sports in our country.

\section{References}

1. Peter O, Bill YI. A notational analysis of elite tennis strategy. J Sports Sci 2001; 19: 707-108.

2. Liemhn WP, Baumgarener TA, Gagnon LH. Measuring core stability. J Strength Cond Res 2005; 19: 583-586.

\section{*Correspondence to}

Zhang Wenli

Shijiazhuang City

Hebei Province

PR China 